\title{
EVALUATION OF REGIONAL LUNG VENTILATION IN DIFFERENT SURGICAL POSITIONS WITH ELECTRICAL IMPEDANCE TOMOGRAPHY
}

\section{Gonçalves, AS; Ribeiro, RA; Macruz, TA; Abreu, LSN; Ferez, D; Falcão, LFR}

Discipline of Anaesthesiology, Pain and Critical Care Medicine, Federal University of São Paulo, Brazil

\section{INTRODUTCTION}

Understanding how mechanical ventilation changes air distribution in the patient's lung is essential to the anaesthesiologist's practice. A skewed distribution can lead to ventilation/perfusion mismatch, and patients submitted to surgeries in various different positions are particularly prone to these complications.
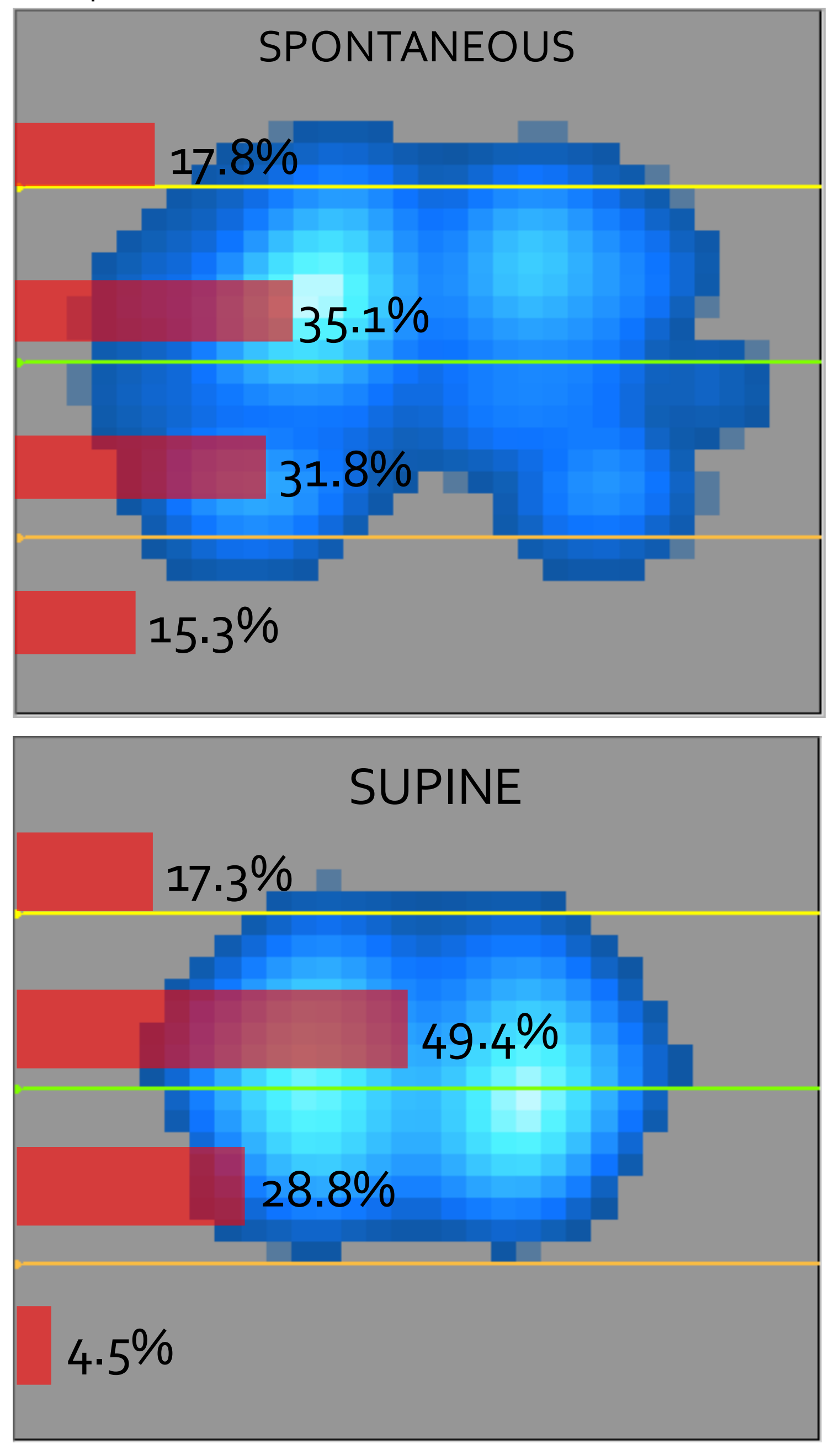

METHODS

Ten healthy patients submitted to elective surgery were monitored with an Electrical Impedance Tomography during the perioperative period. The patients were positioned to each procedure and the assistant anaesthesiologist was blinded to the results of the EIT monitoring. The ventilator was set to VT=8 $\mathrm{mL} / \mathrm{kg}$ of predicted body weight, $\mathrm{PEEP}=5 \mathrm{cmH} 2 \mathrm{O}$, and $\mathrm{FiO} 2=50 \%$. VT and PEEP were kept constant despite changes in patient position and no recruitment maneuvers were made. The proportion of ventilation in the Nondependent region (NDR) and Dependent region (DR) was measured during spontaneous ventilation in supine and during mechanical ventilation in supine, prone and lateral positions.
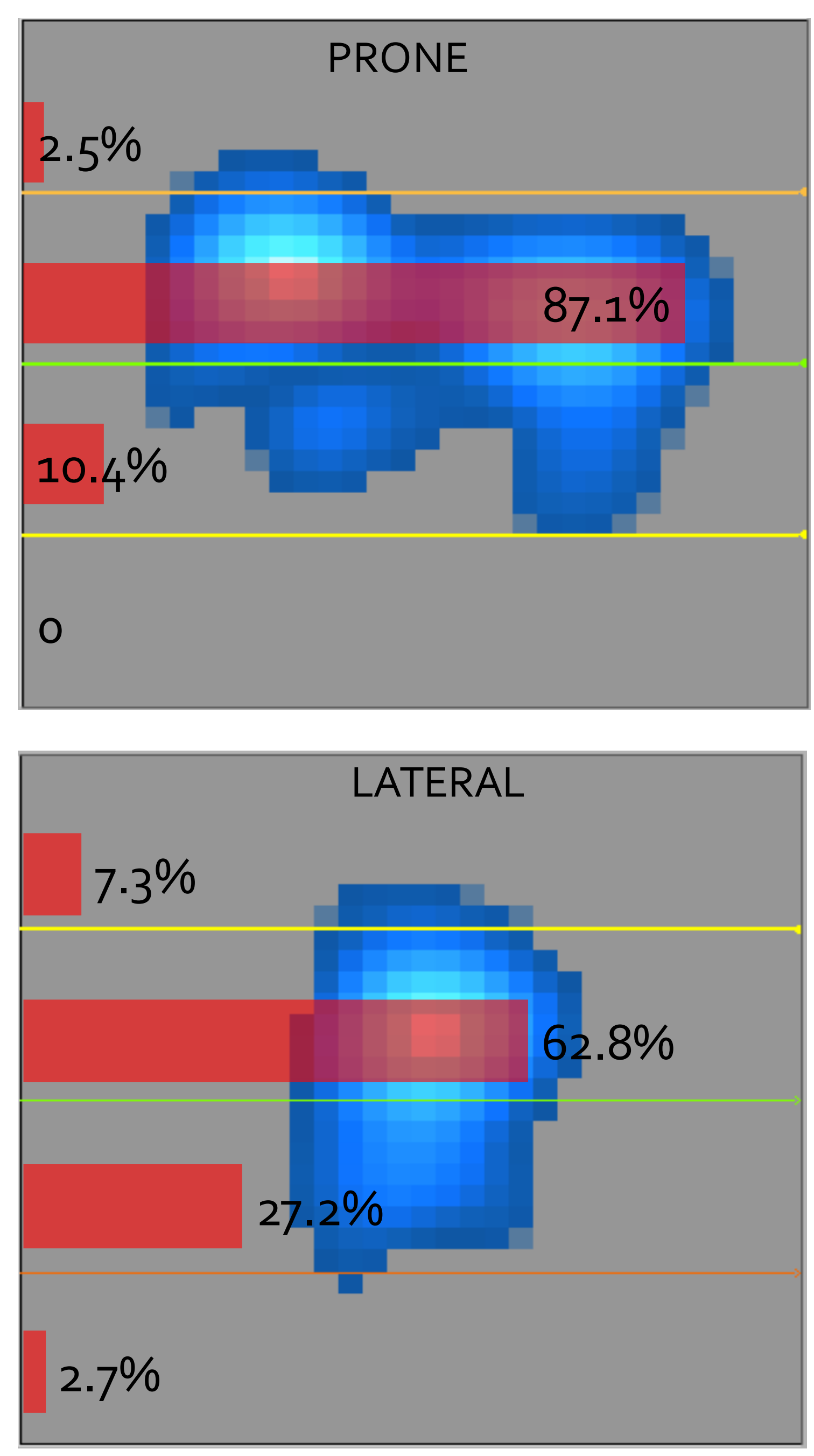

\section{RESULTS}

Before sedation the distribution of ventilation was even between $\operatorname{NDR}(53 \%)$ and DR (47\%). As soon as anaesthesia started there was a noticeable shift of ventilation to NDR. The NDR/DR distribution of ventilation was $66 \% / 34 \%$ in supine, $89 \% / 11 \%$ in prone and $70 \% / 30 \%$ in lateral position.

\section{CONCLUSIONS}

Maintaining mechanical ventilation settings during changing surgical positions, without recruitment maneuvers, can lead to a shift of ventilation distribution to NDR in supine, prone and lateral positions. Further studies are needed to find maneuvers that can promote a less skewed distribution of ventilation in surgical patients.

\section{Euroanaesthesia \\ THE EUROPEAN ANAESTHESIOLOGY CONGRESS}

GENEVA 03-05 JUNE 